\title{
AMÉRICA LATINA. DECISIONES NACIONALES Y SUBVERSIÓN DEL ORDEN VIGENTE
}

Oscar Mañán

Facultad de Ciencias Económicas y Administración

de la Universidad de la República

Los países latinoamericanos experimentan una paradoja: la incertidumbre de la crisis económica que aqueja al mundo desarrollado representa oportunidades para implementar cambios que buscan un desarrollo autónomo. Las experiencias más conspicuas optan por un camino posneoliberal, que nos significa necesariamente cambios estructurales, ni mucho menos poscapitalistas.

Cómo voy a creer, dijo el fulano, que el mundo se quedó sin utopías

Mario Benedetti

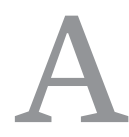

costa sostiene que, además de Ecuador, que emprendió un proceso de cambios desde 2007, debido a "...la crisis del neoliberalismo, desde hace algunos años atrás y con diversas intensidades, se transita paulatinamente por una senda postneoliberal en Argentina, Bolivia, Brasil, Paraguay, Uruguay y Venezuela". ${ }^{1}$ Petras agrupa las diversas experiencias en el "bando progresista", donde tienen cabida los gobiernos que esbozan un discurso antiimperialista, como Venezuela, Bolivia y Ecuador, y los gobiernos que comparten el modelo extractivista neocolonial, como Brasil, Argentina, Uruguay y Perú (de Humala). ${ }^{2}$ Otra caracterización sería distinguir a las experiencias que buscan deliberadamente instituir un nuevo Estado a partir de una nueva Constitución, como es el caso de Bolivia, Ecuador y Venezuela (Estados instituyentes); y aquéllos, como el resto, que simplemente se podrían caracterizar como experiencias de progresismo. México y Colombia serían los casos más controversiales, pues la estrategia de inserción internacional y su alineamiento político sigue los pasos de una institucionalidad internacional acrítica y en su interior tienen grandes dificultades para que sus Estados mantengan el monopolio legítimo de la violencia, lo que cuestiona su misma esencia (Estados fallidos o en descomposición). ${ }^{3}$

Esta oleada de cambios está cruzada por (in)definiciones que encorsetan las trasformaciones más prometedoras y no terminan por tomar el timón de la economía nacional, como tampoco se alientan procesos de integración solidarios entre los países a pesar de los discursos. ${ }^{4}$ Tales definiciones pueden ejemplificarse con la misiva del presidente de Ecuador: "básicamente estamos haciendo mejor las cosas con el mismo modelo de acumulación, antes que cambiarlo, porque no es nuestro deseo perjudicar a los ricos, pero sí es nuestra intención tener una sociedad más justa y equitativa". 5

No obstante, sin cambiar los equilibrios existentes y sin perjudicar a los que controlan los principales recursos, y por tanto las decisiones de la economía, la construcción de una sociedad más justa y equitativa, incluso democrática, no parece ser un objetivo plausible. La oleada de inversión extranjera sumada a una institucionalidad internacional que resguarda sus libres movimientos y eventuales conflictos ante los arrojos de soberanía nacionalista, pero también las condiciones favorables que los Estados brindan y la negativa expresa de utilizar instrumentos de regulación, dificultan la articulación de un sistema nacional de decisiones para el desarrollo.

\section{Modelo de crecimiento EEDDIE}

(extrovertido, extractivista, depredador y dependiente) La constante de los últimos años en la región es un crecimiento económico basado en los precios de las commodities derivados de los recursos naturales, en especial en América del Sur, en el marco de un modelo de acumulación que podrían definirse como nuevo desarrollismo extractivista. ${ }^{6}$ Además de extractivista (en el sentido de saqueo de las reservas de recursos naturales), dicho crecimiento es extrovertido (orientado hacia afuera, impulsado por las exportaciones), depredador (por su relación con la naturaleza biótica y abiótica) y dependiente (de la inversión extranjera directa y el financiamiento externo). Tal modelo es típicamente neocolonial, pues la inversión extranjera directa (IED) es hegemónica en la mayoría de los recursos energéticos, mineros y agrícola-ganaderos de la región. Esta evidencia pone en cuestión la construcción de un sistema nacional de decisiones que apuntale una modalidad de desarrollo integradora de los sectores populares, al igual que cualquier proceso de democratización de acceso a los recursos centrales de la economía (tierra, agua, energía, crédito, etcétera). 
Un reciente informe de CEPAL sostiene que la inversión extranjera en la región llegó en 2011 a 153.448 mil millones de dólares (mmd) superando en un $31 \%$ los fondos respectivos al año anterior. El país más agraciado con los flujos externos de capital fue Brasil ( $66 \mathrm{mmd}$ ), el resto de América del Sur registró aumentos más moderados, en tanto que México y el Caribe tuvieron un amento de $16 \%$, y el Caribe revirtió su situación de los dos últimos años llegando a un crecimiento del 20\% (CEPAL, 2012, pp. 6-7). Desde la visión de CEPAL, la caída verificada en la crisis de 2008-2009 y su burbuja financiera parece despejarse.

El origen dominante de estos flujos de inversión en América Latina y el Caribe es la Unión Europea (UE), de donde proviene el $40 \%$ de la IED, en especial hacia América del Sur con un crecimiento importante, mientras que en México y Centroamérica se mantuvo estable. Estados Unidos sigue siendo la fuente más importante de y se beneficia de algunos procesos de innovación (I+D) y transferencia tecnológica en los sectores de electrónica y automotriz, fundamentalmente. ${ }^{7}$

La discusión sobre la necesidad de la inversión extranjera y su papel para el desarrollo económico de la región es añeja. Furtado, refiriéndose a la discusión de los años 60, manifestaba la dificultad de los Estados para articular las decisiones nacionales con los intereses de las empresas extranjeras cuyos centros (gravitatorios) de interés exceden en mucho a la región. ${ }^{8}$ Incluso, demostraba ya en aquellos años la falacia del argumento de que no existía ahorro interno para impulsar el proceso de ampliación de los mercados domésticos que implicó la industrialización por sustitución de importaciones. En aquel entonces, los fondos domésticos habrían financiado más del $90 \%$ de la inversión, sin embargo, el capital extranjero tuvo

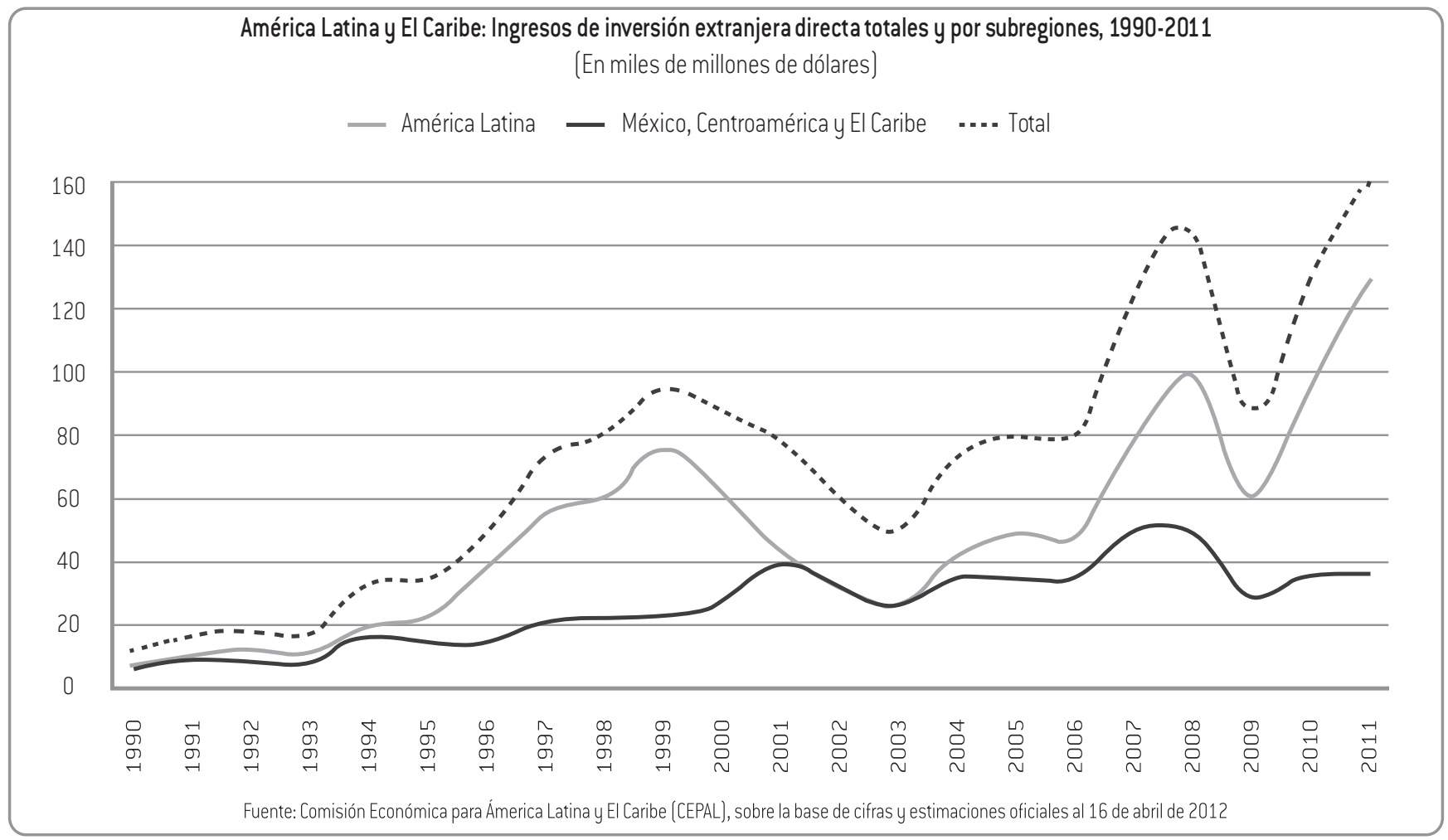

inversión para México y Centroamérica. La IED europea, en particular la española, tuvo como países preferentes a Brasil, Argentina, Colombia y Chile. Los sectores de atracción predilecta de la IED fueron las industrias estratégicas, el sector bancario y la energía. La inversión española se concentró, en la década pasada, en los servicios (86\%), mientras que al sector manufacturero sólo se destino un $12 \%$, primordialmente en Brasil, mientras que el $2 \%$ fue al sector primario. Brasil es el único país que usufructúa inversión fuerte en el sector manufacturero un papel determinante en el financiamiento sin crear capacidades tecnológicas, nuevos sectores o impactos sinergéticos en el encadenamiento sectorial de las economías. Fajnzylber también refirió a la importancia de un sistema de decisiones nacionales a la hora de promover un programa de desarrollo. ${ }^{9}$ Hoy en día es más claro cómo los países que apuestan a recibir el concurso de la inversión foránea relegan los puntos neurálgicos de las decisiones económicas y políticas. 


\begin{tabular}{|c|c|c|c|c|c|c|c|c|c|c|}
\hline \multirow[b]{3}{*}{ País } & \multicolumn{10}{|c|}{$\begin{array}{l}\text { Ingresos de inversión extranjera directa en América latina y El Caribe por país receptor, 2000-2011 } \\
\text { (En millones de dólares y porcentajes] }\end{array}$} \\
\hline & & & & & & \multicolumn{3}{|c|}{2010} & \multirow{2}{*}{$\begin{array}{l}\text { Diferencia } \\
\text { absoluta } \\
2011-2010^{d}\end{array}$} & \multirow{2}{*}{$\begin{array}{l}\text { Diferencia } \\
\text { relativa } \\
2011-2010^{\mathrm{d}}\end{array}$} \\
\hline & $2000-2005^{a}$ & 2006 & 2007 & 2008 & 2009 & 2010 & comparable* & 2011 & & \\
\hline América del sur & 38.003 & 43.410 & 71.839 & 92.500 & 55.478 & 89.632 & 89.620 & 121.318 & 31.698 & $35 \%$ \\
\hline Argentina & 4.296 & 5.537 & 6.473 & 9.726 & 4.017 & 7.055 & & 7.243 & 188 & $3 \%$ \\
\hline $\begin{array}{l}\text { Bolivia (Estado } \\
\text { plurinacional de) }\end{array}$ & 350 & 278 & 362 & 508 & 426 & 672 & & 859 & 187 & $28 \%$ \\
\hline Brasil & 19.197 & 18.822 & 34.585 & 45.058 & 25.949 & 48.506 & & 66.660 & 18.154 & $37 \%$ \\
\hline Chile & 5.047 & 7.298 & 12.534 & 15.150 & 12.874 & 15.095 & & 17.299 & 2.204 & $15 \%$ \\
\hline Colombia & 3.683 & 6.656 & 9.049 & 10.620 & 7.137 & 6.899 & & 13.234 & 6.335 & $92 \%$ \\
\hline Ecuador ${ }^{b}$ & 839 & 271 & 194 & 1.006 & 321 & 157 & 187 & 386 & 199 & $107 \%$ \\
\hline Paraguay ${ }^{b}$ & 48 & 95 & 202 & 209 & 95 & 228 & 186 & 149 & -37 & $-20 \%$ \\
\hline Perú & 1.604 & 3.467 & 5.491 & 6.924 & 5.576 & 7.328 & & 7.659 & 331 & $5 \%$ \\
\hline Uruguay & 393 & 1.493 & 1.329 & 2.106 & 1.620 & 2.483 & & 2.528 & 45 & $2 \%$ \\
\hline $\begin{array}{l}\text { Venezuela (República } \\
\text { Bolivariana de) }\end{array}$ & 2.546 & -509 & 1.620 & 1.195 & -2.536 & 1.209 & & 5.302 & 4.093 & $339 \%$ \\
\hline México $^{\mathrm{e}}$ & 23.275 & 20.006 & 31.313 & 26.889 & 15.959 & 20.208 & 17.726 & 19.440 & 1.714 & $10 \%$ \\
\hline América Central & 2.578 & 5.756 & 7.400 & 7.564 & 4.529 & 6.044 & & 8.246 & 2.203 & $36 \%$ \\
\hline Costa Rica & 626 & 1.469 & 1.896 & 2.078 & 1.347 & 1.466 & & 2.104 & 638 & $44 \%$ \\
\hline El Salvador & 325 & 241 & 1.551 & 903 & 366 & 117 & & 386 & 269 & $231 \%$ \\
\hline Guatemala & 334 & 592 & 745 & 754 & 600 & 806 & & 985 & 179 & $22 \%$ \\
\hline Honduras & 418 & 669 & 929 & 1.006 & 523 & 797 & & 1.014 & 217 & $27 \%$ \\
\hline Nicaragua & 219 & 287 & 382 & 626 & 434 & 508 & & 968 & 460 & $91 \%$ \\
\hline Panamá & 656 & 2.498 & 1.899 & 2.196 & 1.259 & 2.350 & & 2.790 & 440 & $19 \%$ \\
\hline El Caribe & 3.612 & 5.694 & 6.317 & 10.049 & 5.623 & 4.996 & 3.696 & 4.443 & 748 & $20 \%$ \\
\hline Anguila & 60 & 143 & 120 & 101 & 37 & 26 & & 12 & -14 & $-55 \%$ \\
\hline Antigua y Barbuda & 127 & 361 & 341 & 176 & 85 & 101 & & 64 & -37 & $-37 \%$ \\
\hline Bahamas $^{b}$ & 383 & 843 & 887 & 1.032 & 753 & 960 & 580 & 840 & 260 & $45 \%$ \\
\hline Barbados & 118 & 298 & 394 & 470 & 303 & 344 & & .- & .. & .. \\
\hline Belice & 56 & 109 & 143 & 180 & 112 & 101 & & 98 & -3 & $-3 \%$ \\
\hline Dominica & 26 & 29 & 48 & 57 & 42 & 25 & & 25 & 1 & $2 \%$ \\
\hline Granada & 65 & 96 & 172 & 148 & 104 & 63 & & 43 & -21 & $-32 \%$ \\
\hline Guyana & 50 & 102 & 152 & 178 & 164 & 154 & &.. & .. & .. \\
\hline Haití & 12 & 161 & 75 & 30 & 38 & 150 & & 181 & 31 & $21 \%$ \\
\hline Jamaica & 595 & 797 & 752 & 1.361 & 480 & 170 & & .. & .. & .. \\
\hline Monserrat & 2 & 4 & 7 & 13 & 3 & 3 & & 3 & 0 & -3 \\
\hline República Dominicana & 932 & 1.085 & 1.667 & 2.870 & 2.165 & 1.896 & & 2.371 & 475 & $25 \%$ \\
\hline Saint Kitts y Nevis & 84 & 115 & 141 & 184 & 136 & 122 & & 142 & 20 & $16 \%$ \\
\hline San Vicente y las & 43 & 110 & 132 & 159 & 98 & 103 & & 135 & 32 & $31 \%$ \\
\hline Granadinas & & & & & & & & & & $-30 \%$ \\
\hline Santa Lucia & 76 & 238 & 277 & 166 & 152 & 115 & & 81 & -34 & \\
\hline Suriname & 143 & 323 & 179 & 124 & 242 & 113 & & 154 & 42 & $37 \%$ \\
\hline Trinidad y Tobago ${ }^{c}$ & 842 & 883 & 830 & 2.801 & 709 & 549 & 296 & 293 & -3 & $-1 \%$ \\
\hline Total & 67.468 & 74.866 & 116.869 & 137.001 & 81.589 & 120.880 & 120.880 & 153.448 & 36.363 & $31 \%$ \\
\hline \multicolumn{11}{|c|}{$\begin{array}{l}\text { Fuente: Comisión Económica para América Latina y el Caribe (CEPAL) sobre la base de cifras preliminares y estimación oficiales al } 16 \text { de abril de } 2012 . \\
\text { Las cifras para años anteriores a } 2010 \text { pueden no coincidir con informes previos por las revisiones que algunos países realizan. } \\
\text { *Para los países que aún no cuentan con información definitiva de } 2011 \text {, los valores de esta columna se refieren a los ingresos de inversión extranjera en un periodo } \\
\text { de } 2010 \text { (primeros dos o tres trimestres) que permiten hacer una comparación con el mismo periodo de } 2011 . \\
\text { a Promedio simple. } \\
\text { bCifras oficales al tercer trimestre. } \\
\text { c Cifras oficialesal segundo trimestre. } \\
\text { d Dado que algunos países de América Latina no presentan datos sobre } 2011 \text {, la absoluta y la tasa de crecimiento se calcularon según la variación de los últimos } 12 \\
\text { meses durante el último periodo disponible. } \\
\text { e México suele revisar sus datos oficiales al alza durante el mes de mayo. Por esta razón el crecimiento anual se calcula sobre la base de la cifra preliminar referente a } \\
2010 \text {, que fue de } 17.726 \text { millones de dólares, y no a partir d ela última cifra disponible, de } 20.208 \text { millones de dólares }\end{array}$} \\
\hline
\end{tabular}




\section{¿Vuelta al Estado soberano?}

El debate se aviva en la región tras la decisión del gobierno argentino de expropiar las acciones de la empresa española Repsol que controlaba Yacimientos Petrolíferos Federales (YPF). La decisión le permite al gobierno controlar el 51\% de las acciones de YPF. Según las autoridades, la medida se justifica por la falta de inversión de Repsol, que a su vez pone en predicamento la sustentabilidad energética del país. Esta medida que retomaría la soberanía sobre una empresa privatizada en los 90 , que literalmente saqueó al país en los últimos años al repatriar el 94\% de las ganancias, no alienta demasiadas expectativas dado el carácter de sociedad anónima de la petrolera y la falta de controles parlamentarios con que opera. En un país cuyas instituciones son débiles, el sistema político no termina de reconstituirse luego de la atomización de los partidos históricos (peronismo y radicalismo) durante la crisis de 2001-2002. La incertidumbre campea al no divisarse ni un plan estratégico para el complejo energético y menos todavía un programa de desarrollo a mediano plazo. La oposición desconfía de que el móvil de la nacionalización esté simplemente en reforzar el apoyo popular del gobierno y, sobre todo, quedarse con una parte de la renta petrolera para usos electorales. ${ }^{10}$

Días después, se sumó una decisión del gobierno boliviano de expropiar las acciones de una distribuidora y transportadora de electricidad de propiedad también española, Red Eléctrica de España (REE). En este caso deambulan especulaciones políticas, como la supuesta caída de la popularidad del presidente Evo Morales, que ahora rondaría la mitad del nivel que alcanzará cuando ganó la elección de 2010. En tanto que algunos especialistas señalan que el problema de Bolivia es la producción y no la distribución de electricidad. ${ }^{11}$

Las medidas anteriores no solucionan de por sí -ni podrían ocultar, más allá de especulaciones políticaslas dificultades energéticas que viven los países y los niveles de inversión necesarios para sanear su situación en el cortísimo plazo. Esto también es extensible a Brasil y Uruguay, que afrontan dificultades similares, además de que ambos países están volcados a la búsqueda de petróleo y a la producción de energías alternativas. El caso bastante generalizado de toda la región es la carga onerosa de la nueva inversión requerida por la extracción e industrialización de los energéticos y la resistencia, también unánime, a aumentar impuestos directos a las rentas del capital, cuando existen espacios comparativos muy grandes, señalados incluso por CEPAL. ${ }^{12}$

La reacción del gobierno español en defensa de Repsol no se hizo esperar, al igual que el exhorto de la UE sobre posibles represalias y demandas en los tribunales internacionales en contra de la acción del gobierno argentino que habría violado las reglas del juego comprometidas con la IED. Una de las cosas que permite adelantar la coyuntura de crisis internacional es lo poco probable que las represalias puedan cambiar o torcer las decisiones comentadas. No obstante, en Argentina se especula si en realidad el gobierno no estaría buscando la sustitución de los socios (quizás ahora por alguna multinacional americana, p. ej., Exxon o Chevron) y no necesariamente mantener el control nacional del complejo energético.

Cualquiera sea el desenlace, la institucionalidad de Bretton Woods y el sistema de gestión capitalista propio del neoliberalismo se verían debilitados. Los países de América Latina, con la excepción de México y Colombia, resaltaron el legítimo ejercicio de la soberanía por parte de Argentina y rechazaron el tono colonial con que España y la UE desafiaron la medida.

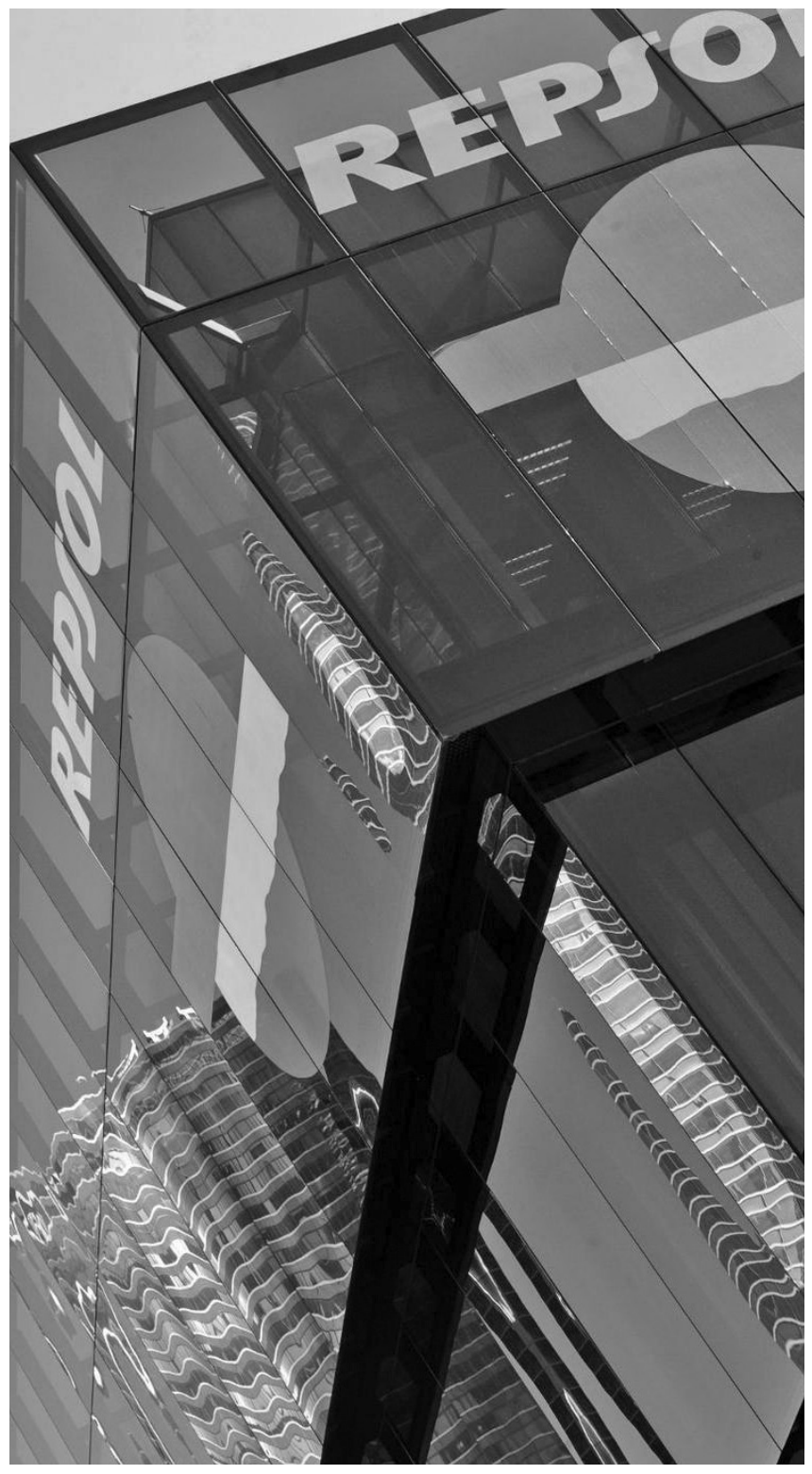




\section{Poder y construcción de un sistema nacional de decisiones estratégicas}

¿Será imposible soñar con otro Estado que elija inundar al mercado con decisiones colectivas que rijan las decisiones individuales, como pensaba Prebisch $?^{13} \dot{¿}^{\text {No será }}$ más utópico aún pensar que el futuro se parezca al hoy, como decía Vuscovic? ${ }^{14}$ Los problemas y oportunidades de la región están cruzados por factores exógenos que dependen de la coyuntura mundial y otros elementos endógenos que básicamente descansan en los equilibrios de clase (siempre dinámicos) de los países.

El aumento de los flujos de inversión extranjera en la década pasada hacia la región, como el crecimiento importante en el año 2011 que explican el dinamismo de los modelos EEDDIE, pudiera revertirse rápidamente. Son elementos que juegan en tal sentido, la demanda de fondos que necesitará la reconstrucción europea y que saldrán de la repatriación de sus capitales; y la potencialidad de la región como imán de los flujos mundiales de capital pierde peso respecto a las oportunidades del este de Europa. Ambos factores exógenos potenciarían aún más el proceso de desinversión en la producción energética y sostienen el saqueo liso y llano de corto plazo con las consecuencias conocidas para el ambiente y para el stock de recursos en dichos sectores. De aquí que decisiones del tipo de las tomadas por Argentina o Bolivia, independientemente de su éxito, sean imprescindibles para simplemente asegurar la sustentabilidad productiva y la demanda energética que implica.

El modelo de crecimiento que se identificaba como EEDDIE tendrá que superar necesariamente su carácter extractivista y primarizado, por lo tanto deberá corroer las bases materiales que lo sostienen, en particular las alianzas de clase que lo hacen posible. Esto implica la construcción de otro Estado donde la dominación comience a integrar sectores obreros, campesinos e indígenas en un sentido de complementariedad y respeto de las culturas respectivas. Los gobiernos progresistas tendrán que desafiar decididamente el status quo, cuestión que no hacen por miedo a perder legitimidad y decisiones debido a la creencia errónea de que no poseen el poder. Dussel explicaba que el poder no se toma ni se tiene, se ejerce; y se ejerce a nombre de algún colectivo. ${ }^{15}$

Los progresismos en general ejercieron el poder apoyados en: 1) la institucionalidad global que incluye a las llamadas instituciones de Bretton Woods (FMI, $\mathrm{BM}, \mathrm{OMC}$, Bancos Regionales), las IFI (instituciones financieras internacionales) y sus sistemas de valuación de riesgos vigentes y la IED de movilidad irrestricta; 2) equilibrios de clase domésticos que implica el control de recursos naturales por grupos tradicionales o por las mismas transnacionales, asegurando la decisiones mercantiles y la libre movilidad de capitales, con una sociedad política tradicional apoyada en una tecnocracia que gestiona el aparato administrativo-militar de la dominación; y 3) una sociedad civil organizada que de alguna manera legitima y obtiene ciertos réditos, ONG, organizaciones sociales que luchan por el avance de determinados derechos humanos y reivindicaciones básicas de los sectores populares, las gremiales y sindicatos de trabajadores que buscan reforzar sus ingresos que arrastran retrasos de las décadas neoliberales, diversas asociaciones y movilización popular alentada por las fuerzas tradiciones de la izquierda vernácula.

\section{Diez propuestas para el debate}

1) Romper con el modelo de crecimiento EEDDIE implica repensar la inserción internacional de los países, una de las ventajas en América del Sur respecto a México y Centroamérica es cierta diversificación de los destinos de exportación que hace posible pensar en una menor vulnerabilidad. Ello implicará romper con algunos corsets que impone el orden institucional que rige al sistema capitalista.

2) Pero a su vez necesitará una actitud proactiva del Estado que refuerce una política industrial coherente con un sistema nacional de decisiones estratégicas, eso exigirá un reordenamiento estructural de la economía.

3) Un cambio estructural en la economía no se logra sin cambiar las fuentes que apoyan las decisiones políticas esenciales, es decir, sin ejercer el poder basado en otros colectivos e instituciones diferentes a las actuales.

4) Desde el punto de vista económico implicará promover un desarrollo sectorial congruente con los intereses que formarán el nuevo pacto dominante en la sociedad y eso requerirá una estructura de precios y una rearticulación de las cargas y beneficios entre los agentes económicos que reoriente los patrones predominantes de inversión.

5) Lo anterior se traduce en un disciplinamiento de los agentes privados receptores de rentas, sistemas de aranceles, subsidios y regulaciones que permitan la transformación productiva deseada.

6) El financiamiento del desarrollo y las fuentes elegidas para tales efectos debe subordinarse al conjunto de decisiones nacionales, por lo tanto, el sistema tributario tendrá un papel importante conjuntamente con la política fiscal para distribuir de manera justa las cargas y beneficios del sistema económico.

7) La inversión privada nacional y extranjera debe adecuarse a las decisiones estratégicas y el sistema de incentivos que se promuevan para articularse con ellas. Las renuncias fiscales o las preferencias otorgadas que sean imprescindibles deberán articularse con la eficacia de los objetivos perseguidos y con un plan 
estricto para su cumplimiento en tiempos prudentes. La eficiencia económica no debe seguir únicamente los designios mercantiles del lucro individual sino comprenderse de forma ampliada en el conjunto de decisiones estratégicas definidas.

8) El papel de la inversión pública es determinante de cara a generar encadenamientos productivos con nuevos eslabones en sectores con mayor contenido de valor. Pero a la vez, para ir cooptando espacios de decisiones para la esfera pública que antes permanecían en el ámbito privado.

9) La misma CEPAL, ${ }^{16}$ que no es una institución que pretenda la subversión del orden vigente, sostiene la necesidad primordial de "retener la propiedad estatal de los principales recursos naturales de exportación o instrumentar impuestos o regalías que graven las actividades extractivas asociadas a la producción primaria (cobre, petróleo, minerales) e incentiven su sostenibilidad ambiental".

10) Las medidas que refuerzan la soberanía en el conjunto de decisiones estratégicas, en sectores alimentarios básicos, energéticos, en las industrias metalmecánicas, manufactureras y de construcción implicadas en el desarrollo nacional deben promoverse.

Referencias

${ }^{1}$ Acosta, Alberto (2012), "El retorno del Estado. Primeros pasos posneoliberales mas no poscapitalistas”, Revista Tendencia, no. 13.

${ }^{2}$ Petras, James (2012), "El capitalismo extractivo y las diferencias en el bando latinoamericano progresista", Rebelión 8-5-12; disponible en: http://www.rebelion.org/noticia. php?id=149207 (9/05/2012).

${ }^{3}$ Mañán, Oscar (2011), “Los Estados pos-neoliberales en América Latina”, ponencia en Encuentro Pensamiento Crítico, Sujetos Colectivos y Universidad, organizado por el NúcleoRed Interdisciplinario de la Universidad de la República, Montevideo 21 de septiembre 2011. Si la idea de progresismo se definiera como "progreso social", basado en cierta idea de "solidaridad con la pobreza" pero sin desafiar las estructuras básicas de la economía y por ende el status quo, además dejando de lado el ciclo político (de izquierdas o derechas), Chile también entraría en tal categoría. Vuskovic, Pedro (1993), La pobreza, desafío teórico y estratégico, México, IIE-Unam.

${ }^{4}$ Cuba y Venezuela son las excepciones honrosísimas. Cualquiera de los dos países, el primero desde la revolución, el segundo con "el chavismo" y su también revolución bolivariana han tenido una actitud colaborativa y solidaria muy importante con la región. Venezuela ayuda financieramente a varios países comprando sus deudas cuando no pueden acudir a los mercados internacionales, o absorbiendo empresas financieras en problemas, vendiendo petróleo a precios solidarios o cobrando en especies. Cuba, con sus limitaciones de fondos a puesto siempre a disposición de la región su sistema desarrollado de salud y sus avances médicos como también sus avances en educación y su sistema público de formación de profesionales en varias áreas.

${ }^{5}$ Correa apud Alberto Acosta, op. cit.

${ }^{6}$ Verdum, Ricardo (2009), El nuevo extractivismo desarrollista en Sudamérica: Disponible en: http://www.extractivismo.com/ noticias/verdum-extractivismo-desarrollista-sudamerica. html (1/11/2011).

${ }^{7}$ CEPAL (Comisión Económica para América Latina y el Caribe) (2012), Inversión extranjera directa, Santiago de Chile. CEPAL (2011), Panorama de la Inserción Internacional de América Latina y el Caribe 2010-2011. La región en la década de las economías emergentes, Santiago de Chile, CEPAL-ONU.

${ }^{8}$ Furtado, Celso (1969), "La estructuración de la economía internacional”, C. Furtado, La concentración del poder económico de Estados Unidos y sus reflejos en América Latina, Capital Federal, Cuba, Centro Editor de América Latina.

${ }^{9}$ Fajnzylber, Fernando (1983), “América Latina: Imagen fiel o reflejo deformado de la industrialización en países avanzados”, En F. Fajnzylber, La industrialización trunca de América Latina, México, Nueva Imagen.

${ }^{10} \mathrm{El}$ sistema político argentino es complejo, y el debate al respecto arduo: para muchos, el sistema de privatizaciones llevado a cabo en los noventa no se desmantela aún y sigue siendo un factor de enriquecimiento para grupos nacionales afines al gobierno. No obstante, desde afuera del país, y dado el desencanto que los progresismos regionales generan en la población que esperaba cambios estructurales de importancia, se ve en la expropiación de la petrolera como alentadora para desafiar los espacios de control que guarda el capital transnacional.

${ }^{11}$ Zarati, Francesco (2012), "Nacionalización en Bolivia no soluciona crisis energética”, El Nuevo Diario, disponible en: http://www.elnuevodiario.com.ni/internacionales/250022 (9/5/2012).

${ }^{12}$ CEPAL (2010), La hora de la igualdad: brechas por cerrar, caminos por abrir, Santiago: ONU/CEPAL, disponible en: http:// www.eclac.cl/cgi-bin/getProd.asp?xml=/publicaciones/ $\mathrm{xml} / 0 / 39710 / \mathrm{P} 39710 . \mathrm{xml} \& \mathrm{xsl}=/ \mathrm{pses} 33 / \mathrm{tpl} / \mathrm{p} 9 \mathrm{f} . \mathrm{xs}$ \&base=/ pses33/tpl/top-bottom.xsl (9/5/2012).

${ }^{13}$ Prebisch, Raúl (1983), "Cinco etapas de mi pensamiento sobre el desarrollo” en El Trimestre Económico, no. 198, abril-junio.

${ }^{14}$ Vuskovic, Pedro, G. Vidal, P. Paz, y E. Ruiz (1991), Hacia un proyecto alternativo para América Latina, México, IIE-UNAM.

${ }^{15}$ Dussel, Emrique (2006), 20 Tesis de Política, México, Siglo XXI.

${ }^{16}$ CEPAL (2010), La hora de la igualdad: brechas por cerrar, caminos por abrir. Santiago de Chile, ONU/CEPAL, disponible en: http://www.eclac.cl/cgi-bin/getProd.asp?xml=/ publicaciones/xml/0/39710/P39710.xml\&xsl=/pses33/tpl/ p9f.xsl\&base=/pses33/tpl/top-bottom.xsl (9/05/2012). 